\title{
Cecal epidermoid cyst: a neonatal case with clinicopathological consideration
}

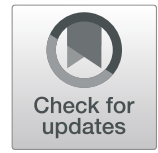

\author{
Joo-Young $\mathrm{Na}^{1}$ (D), Soo-Hong $\mathrm{Kim}^{2}$ (D) and Narae Lee ${ }^{3^{*}}$ (D)
}

\begin{abstract}
Background: Only 10 cases of cecal epidermoid cyst (CEC) have been reported in the literature. Furthermore, its pathogenesis remains unclear. We report a rare case of congenital CEC in neonate, and discuss its clinicopathological findings.

Case presentation: A cystic lesion was incidentally identified in the retroperitoneal area of the abdominal right lower quadrant during a routine prenatal ultrasonography (US), prompting an ileocolectomy 3 days after birth. This congenital cyst was composed of mucosal lining cells and submucosal connective tissues, and the inner lining mucosa was composed of stratified squamous epithelium and focally mucin-producing ciliated epithelium. Based on the macroscopic and microscopic findings, the cystic lesion was diagnosed as a congenital cecal epidermoid cyst.

Conclusions: The management of a fetal abdominal mass should be tailored individually, considering that epidermoid cysts can occur in the cecum during the perinatal period. We report the clinicopathological findings in this case, including its possible pathogenesis.
\end{abstract}

Keywords: Congenital, Cecum, Epidermoid cyst, Neonate

\section{Background}

In the literature, only 10 case of cecal epidermoid cysts (CECs) have been reported $[1,2]$, with its pathogenesis remaining unclear. CEC can be congenital or acquired in origin. In the congenital form, it is thought to develop from ectodermal implantation during embryogenesis and development, whereas in the acquired form, it is thought to develop from epithelial implantation secondary to previous trauma or surgery $[3,4]$. Additionally, epidermoid cysts are more commonly found in the mediastinum, head and neck, sacrococcygeal area, central nervous system, and gonads [3]. Thus, we report a case of congenital CEC and discuss its clinicopathological findings and possible pathogenesis.

\footnotetext{
*Correspondence: nahrae111@gmail.com

${ }^{3}$ Department of Pediatrics, Pusan National University Children's Hospital, 20, Geumo-ro, Mulgeum-eup, 50612 Yangsan, Republic of Korea

Full list of author information is available at the end of the article
}

\section{Case presentation}

A 28-year-old woman underwent regular follow-ups at an antenatal clinic, without needing any medication. At 24 weeks of gestation, an intra-abdominal cystic mass, approximately $2.0 \times 1.5 \mathrm{~cm}$ in size, was found during routine prenatal ultrasonography (US). Its size increased to $3.5 \times 2.4 \mathrm{~cm}$ at 32 weeks of gestation, and thereafter, it ceased to grow until delivery. The amniotic fluid index at 32 weeks of gestation was $1.5 \mathrm{~cm}$, and this was maintained at $1.3 \mathrm{~cm}$ by 36 weeks of gestation. Eventually, the male neonate was born at 38 weeks and 2 days of gestation via normal spontaneous vaginal delivery, with Apgar scores of 9 and 10 at 1 and 5 min, respectively. He had a body weight of $3500 \mathrm{~g}\left(50^{\text {th }}\right.$ percentile), height of $49.0 \mathrm{~cm}$ (45th percentile), and head circumference of $35.5 \mathrm{~cm}$ (55th percentile). Initial physical examination revealed a soft abdomen with no distention.

Abdominal US performed $25 \mathrm{~h}$ after birth showed a large cyst $(4.2 \times 2.3 \times 4.2 \mathrm{~cm})$ with echogenic material, fluid, and calcification, which originated from the 
retroperitoneum and was located in front of the inferior vena cava and descending aorta (Fig. 1a). Due to the echogenic shadowing of the calcific components, we decided to perform magnetic resonance imaging (MRI) to rule out the possibility of a retroperitoneal teratoma. At 2 days of age, contrast-enhanced MRI of the abdomen was performed for further evaluation. Pre-contrast coronal T2-weighted MRI showed an intermediate to high signal intensity (SI) of a heterogeneous mass with a small low SI component. Further contrast-enhanced fatsaturated T1-weighted MRI of the coronal and transverse views revealed a cystic mass $(4.6 \times 4.5 \times 5.3 \mathrm{~cm})$ with an air-fluid level and multiple minute low SI components (Fig. 1b, c). Moreover, an increasing radiolucent cystic mass in the right lower quadrant (RLQ) began to appear $8 \mathrm{~h}$ after birth on serial infantography (Fig. 2). The patient underwent emergency laparotomy performed by a pediatric surgeon on day 3 of life. Under general anesthesia, the cystic mass was exposed, and over $20 \mathrm{~mL}$ of air and dark brown mucinous fluid were aspirated through a syringe (Fig. 3a). The cystic mass was attached to the cecum, prompting the need for an ileocolectomy with end-to-end anastomosis. Five days post-surgery, the patient started feeding with mother's milk, and the postoperative course was uneventful. $\mathrm{He}$ was discharged 10 days after the surgery without any complications.
On macroscopic examination, a cyst was identified without any macroscopic connection to the cecal lumen. The cyst contained a dark brown mucinous fluid, and the mucosal and serosal surfaces of the cecum were unremarkable (Fig. 3b). On microscopic examination, cyst wall was located at the subserosal layer of the cecal wall, composing of mucosal lining cells and submucosal connective tissues. The cyst cell lining was composed of mature, keratinized, or non-keratinized stratified squamous epithelium and focally mucin-producing ciliated stratified epithelium; however, there were no findings of gastrointestinal mucosal epithelium in the entire cyst and there was no smooth muscle outer layer in the cystic wall, except for an attached portion of the cecal wall. Transition areas between the squamous and mucinproducing ciliated epithelia were noted in some foci. Immunohistochemical examination revealed that the colonic mucosa was reactive to MUC2, while the mucinproducing ciliated epithelium of the cystic mucosa was reactive to MUC5AC (Fig. 4). The boy has had no further symptoms and is doing well. We are scheduled to follow up at age 6 months with abdominal US.

\section{Discussion and conclusions}

The present report describes a case of CEC in a newborn. Only 10 CECs have been reported in English literature, with the only one pediatric patient being an 8-

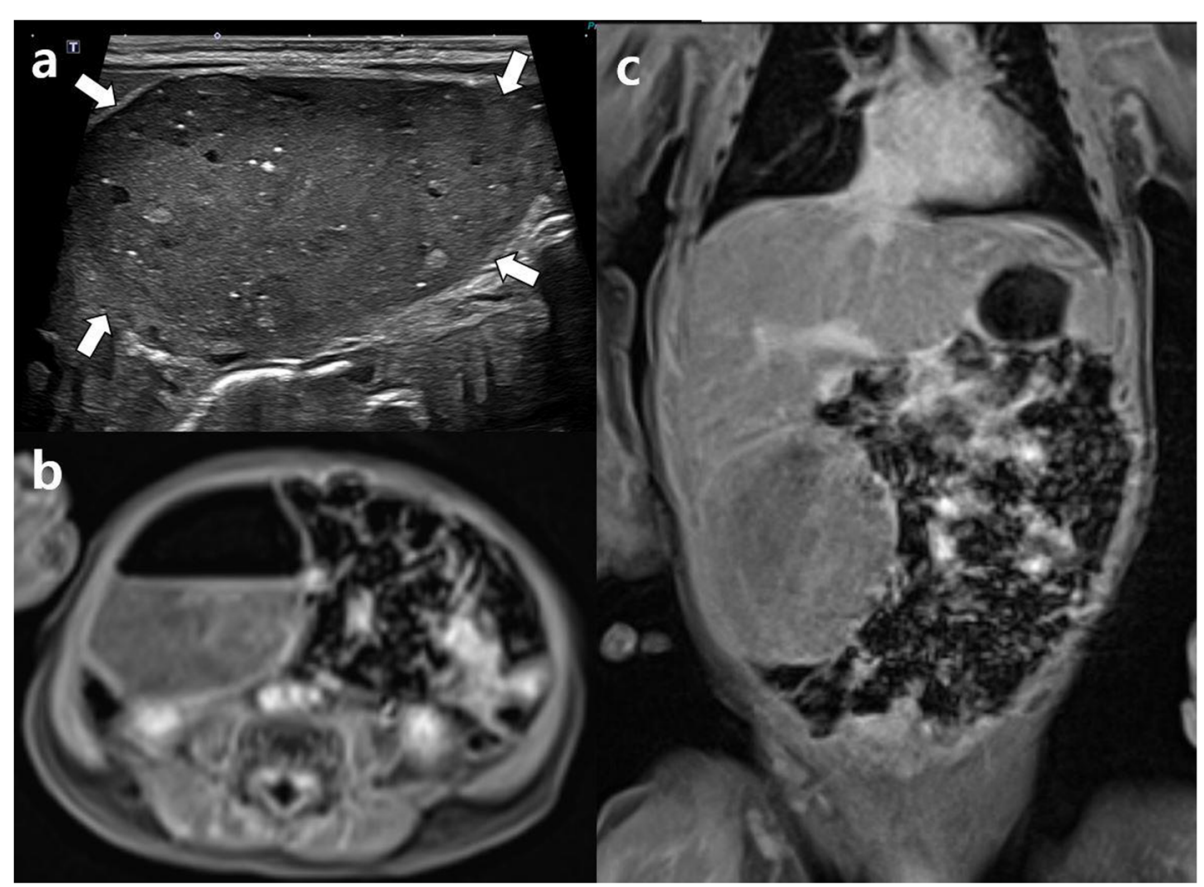

Fig. 1 a A transverse sonogram shows a cyst with echogenic material, fluid, and calcification (arrows). It originated from the retroperitoneum and is located in front of the inferior vena cava and descending aorta. The size of the cyst is $4.2 \times 2.3 \times 4.2 \mathrm{~cm}$. Contrast-enhanced fat-saturated T1weighted MR image of transverse $(\mathbf{b})$ and coronal $(\mathbf{c})$ view reveal a cystic mass with air-fluid level and multiple tiny low signal intensity component. Size of cystic mass is $4.6 \times 4.5 \times 5.3 \mathrm{~cm}$ 


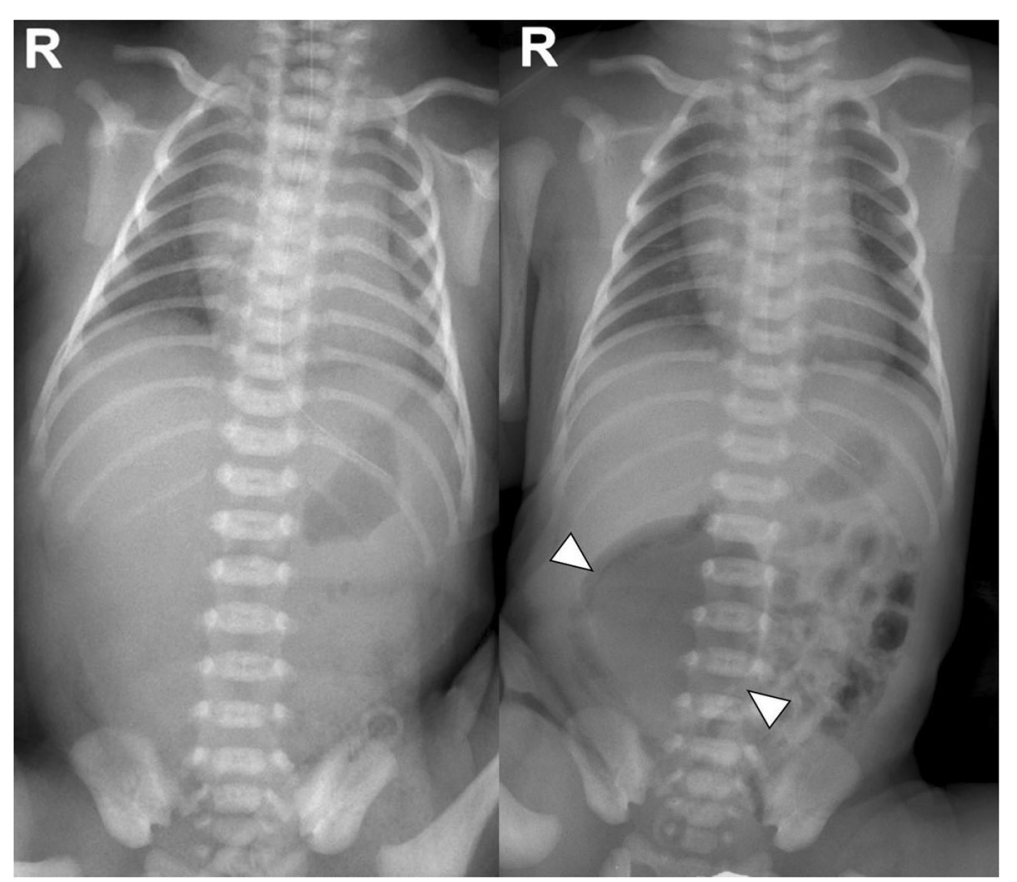

Fig. 2 Infantography shows a nonspecific bowel gas pattern $1 \mathrm{~h}$ after birth (left). Eight hours after birth, a radiolucent lesion at the abdominal right lower quadrant appears, with an interval increase in the size of the radiolucent lesion to $5.2 \times 5.1 \mathrm{~cm}$ at $48 \mathrm{~h}$ after birth (arrowheads) (right)

year-old girl [1,2]. Epidermoid cysts are generally considered sequestration cysts that may be congenital, but some CEC cases were attributed to iatrogenic implantation of epidermal fragments by surgical devices during the previous abdominal operation, such as appendectomy or cesarean surgery [2]. With recent advances in US techniques, fetal abdominal cysts are being reported more often, with ovarian cysts as the most common type in the fetal period [5]. CEC clinical diagnosis remains difficult because it can be confused with ovarian cysts, lymphatic cysts, mesenteric cysts, intestinal duplication, appendiceal mucocele, and meconium pseudocyst, especially if the diagnosis is established in the prenatal period [6]. The treatment of choice for CEC is surgical resection. Since residual squamous epithelial tissues may lead to recurrence and have malignant potential, complete removal is warranted $[7,8]$. Although accurate preoperative diagnosis allows appropriate surgical planning and provides a good prognosis, this becomes difficult for neonatal CECs.

Two pathogenic mechanisms have been proposed for congenital sequestration. One mechanism suggests that ectodermal implantation occurs at the time of neural groove closure during embryogenesis; however, some researchers have postulated that given the location of the cecum and the neural groove or other epithelial fusion lines, this mechanism would be unusual [3]. Another mechanism is that the origin of the congenital

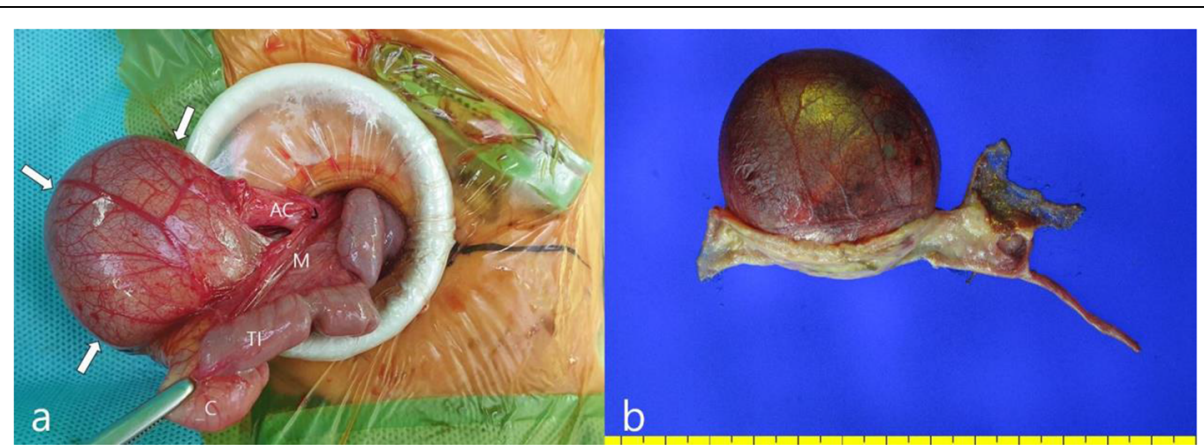

Fig. 3 a Intraoperative photograph of the cyst (arrows), and a macroscopic examination shows (b) a cyst measuring $5.0 \times 6.6 \mathrm{~cm}$ in size is noted, which is attached at the serosal side of the cecum. There is no connection between the cyst and the cecal lumen on macroscopic examination. AC: Ascending colon; C: Cecum; TI: Terminal lleum; M: Mesentery 


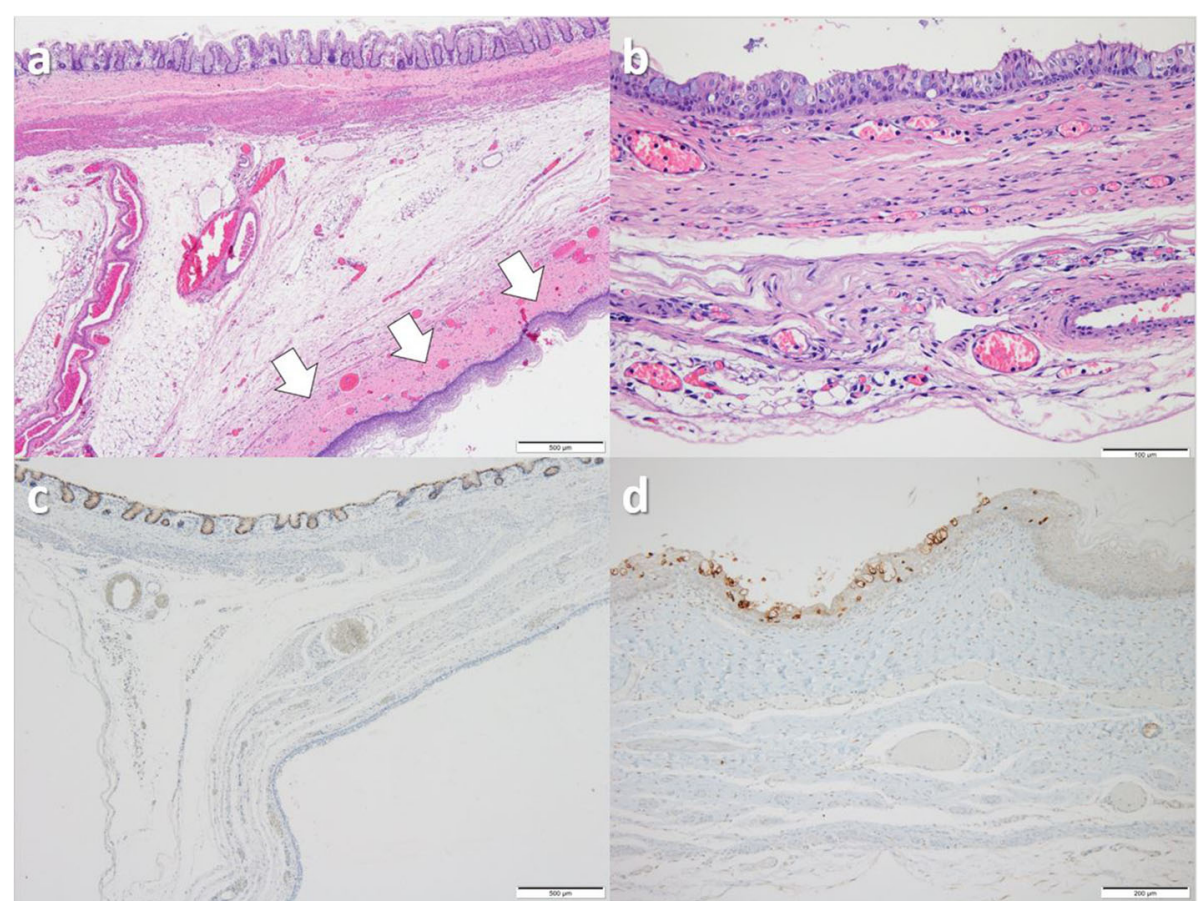

Fig. 4 The cyst is located at the subserosal layer of the cecal wall (arrows), which is composed of stratified squamous epithelium and submucosal connective tissues $(\mathbf{a}, \times 40)$, and the inner mucosal lining is focally composed of mucin-producing ciliated epithelium in some foci $(\mathbf{b}, \times 200)$. Immunohistochemical staining shows that the cecal mucosa is reactive to MUC2 $(\mathbf{c}, \times 40)$, while the cystic mucosa is reactive to MUC5AC (,$\times 100)$

heterotopic tissue may have transpired during the intrauterine rotation of the gut back into the abdominal cavity, especially since the cecum is one of the last elements to re-enter the abdomen [4]. Furthermore, the fact that most CECs occur in the subserosal layer supports this mechanism. In the present case of congenital CEC, heterotopic epithelial tissue was located in the subserosal layer, which is suggestive of ectodermal implantation during intrauterine rotation of the gut. Additionally, mucin-producing ciliated stratified epithelium was identified in this case and this epithelium resembled a bronchial epithelium. This finding could suggest a possible pathomechanism which may be related to the bi-differentiation of heterotopic ectodermal inclusion tissue. We hypothesized that ectodermal tissue was sequestrated in the subserosal layer of the cecum during the rotation of the gut back into the abdominal cavity, wherein these tissues differentiated into both squamous and mucinproducing ciliated epithelium. A previous report suggested that the most likely explanation for CEC development and its sharing of the cecal muscular wall is the result of aberrant embryonic ectodermal implantation during embryogenesis [9]. Our present case showed a subserosal cyst composed of squamous mucosa and submucosal connective tissue, which supports the aforementioned proposed mechanism.
Furthermore, immunohistochemical phenotypes of cecal and cystic mucosal epithelium were different; colonic mucosa was reactive to intestinal mucin MUC2, while the mucosa lining the cyst wall was reactive to gastric and bronchial mucin MUC5AC. When we evaluated the serial radiographs in this case, the RLQ intraluminal gas, which initially did not appear until after birth, continuously expanded. These findings suggest that the cyst was connected to the intestinal lumen, even though the macroscopic examination revealed no connection between two. On microscopic examination, there was one focus of the junction between the cecal and squamous epithelium which was located in the cecal muscularis propria, suggesting a microscopic fistula. Thus, we assumed that the two lumens may have been connected through the microfistula.

In conclusion, considering that epidermoid cysts can develop in the cecum during the perinatal period, the management of a fetal abdominal mass should be tailored individually. Moreover, the possibility of CEC should be considered in the differential diagnosis of subserosal cysts in the cecal area, and the cyst should be completely removed to achieve a good prognosis.

\section{Abbreviations}

CEC: Cecal epidermoid cyst; MRI: Magnetic resonance imaging; MUC2: Mucin 2; MUC5AC: Mucin 5AC; RLQ: Right lower quadrant; SI: Signal intensity 


\section{Acknowledgements}

We thank the parents of our patient for their cooperation and for providing consent for publication.

\section{Authors' contributions}

$\mathrm{NL}$ were involved in the clinical management of these patients and collected clinical details. NJY did pathological examination and provide photographs of this case report. KSH performed the operation and gave his findings with photographs. All authors read and approved the final manuscript.

\section{Funding}

This study was supported by a 2021 research grant from Pusan National University Yangsan Hospital 2021 to Dr. Narae Lee.

\section{Availability of data and materials}

All data generated or analyzed during this study are included in this published article.

\section{Declarations}

\section{Ethics approval and consent to participate}

All this study complied with the requirement of "The Ethics of Clinical Research" issued by Ministry of Health and Welfare, Korea. All procedures performed were in accordance with the ethical standards of "Pusan National University School of Medicine Research Committee" (IRB no. 05-2021-126).

\section{Consent for publication}

A written informed consent was obtained from the parents of patients for publication of this case report.

\section{Competing interests}

The authors declare that they have no competing interests.

\section{Author details}

'Department of Pathology, Pusan National University Yangsan Hospital, Yangsan, Republic of Korea. ${ }^{2}$ Department of Pediatric Surgery, Pusan National University Children's Hospital, Yangsan, Republic of Korea. ${ }^{3}$ Department of Pediatrics, Pusan National University Children's Hospital, 20, Geumo-ro,

Mulgeum-eup, 50612 Yangsan, Republic of Korea.

Received: 11 June 2021 Accepted: 8 September 2021

Published online: 20 September 2021

\section{References}

1. Tominaga T, Nonaka T, Fukuda A, Moriyama M, Oyama S, Ishii M, Sawai T, Ueki N, Nagayasu T. Epidermoid cyst of the cecum resected by singleincision laparoscopic colectomy: a case report. Surg Case Rep. 2021;7:57. https://doi.org/10.1186/s40792-021-01138-2.

2. Park JY, Kim YW, Lee KY, Sung JY. Epidermoid cyst of the cecum. Ann Coloproctol. 2015;31:37-9 Epub 2015 Feb 28.

3. Lao W, Stark R, Lendvay TS, Drugas GT. Cecal dermoid cyst. J Ped Surg Case Rep. 2014;2:347-9. https://doi.org/10.1016/j.epsc.2014.06.015.

4. Andiran F, Dayi S, Caydere M, Dilmen G, Dilmen U. Epidermoid cyst of the cecum. J Pediatr Surg. 1999;34:1567-9. https://doi.org/10.1016/50022-3468(99)90133-1.

5. Catania VD, Briganti V, Di Giacomo V, Miele V, Signore F, de Waure C, Calabrò GE, Calisti A. Fetal intra-abdominal cysts: accuracy and predictive value of prenatal ultrasound. J Matern Fetal Neonatal Med. 2016;29:1691-9. https://doi.org/10.3109/14767058.2015.1059812.

6. Sahoo MR, Gowda MS, Behera SS. Unusual site and uncommon presentation of epidermoid cyst: a rare case report and review of literature. BMJ Case Rep. 2013;2013:bcr2012007907. https://doi.org/10.1136/bcr-2012-007907.

7. Kim HC, Lee HL, Lee SH, Kim GY. Squamous cell carcinoma arising from a presacral epidermoid cyst: CT and MRI findings. Abdom Imaging. 2008;33: 498-500. https://doi.org/10.1007/s00261-007-9287-0.

8. Wu X, Chen C, Yang M, Yuan X, Chen H, Yin L. Squamous cell carcinoma malignantly transformed from frequent recurrence of a presacral epidermoid cyst: report of a case. Front Oncol. 2020;10:458. https://doi.org/1 0.3389/fonc.2020.00458.

9. Mady HH, Melhem MF. Epidermoid cyst of the cecum of an elderly man with no previous history of surgery: a case report and review of literature. Int J Colorectal Dis. 2002;17:280-3. https://doi.org/10.1007/s00384-001-0386-z.

\section{Publisher's Note}

Springer Nature remains neutral with regard to jurisdictional claims in published maps and institutional affiliations.
Ready to submit your research? Choose BMC and benefit from:

- fast, convenient online submission

- thorough peer review by experienced researchers in your field

- rapid publication on acceptance

- support for research data, including large and complex data types

- gold Open Access which fosters wider collaboration and increased citations

- maximum visibility for your research: over $100 \mathrm{M}$ website views per year

At BMC, research is always in progress.

Learn more biomedcentral.com/submissions 